\title{
Exercise and Osteoarthritis: Not Necessarily an All-or-Nothing Proposition!
}

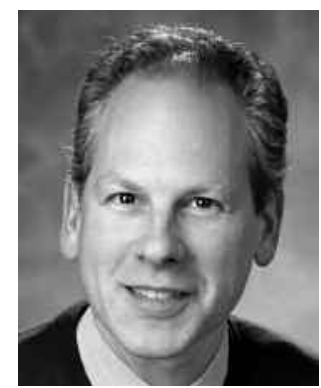

Often the mind-set at the start of a new calendar cycle which may take the form of a New Year's resolution - is to adopt healthy behaviors that promote and sustain good health and reduce the risk of significant morbidity and premature mortality. Three of the leading causes of mortality in modern society are coronary heart disease, cancer, and stroke $^{1,2}$. A risk reduction strategy for cardiovascular disease includes improving control of known risk factors, for example, ameliorating an unfavorable lipid profile and enhancing control of hypertension and diabetes mellitus ${ }^{3}$. Similarly, the risk of malignancy is profoundly influenced by unhealthy consumption of tobacco and excessive alcohol $^{4,5,6}$. Reduced levels of these products are frequent targets of health improvement resolutions to diminish one's susceptibility to adverse cardiovascular events, incident cancer, and all-cause mortality.

Thus the incorporation of regular forms of physical activity into one's daily and weekly routine is frequently heralded at the beginning of the new year. Exercise has been demonstrated to reduce incident cardiovascular disease, cancer, and overall mortality $7,8,9,10,11$. However, in the realm of the musculoskeletal system, is the relationship of exercise to arthritis health necessarily and unequivocally beneficial? In this issue of The Journal Fries, et al ${ }^{12}$ implore the rheumatology community to advocate strongly for increasing physical activity in society at large as a strategy with clear-cut benefit for the prevention and treatment of osteoarthritis (OA) of the knee. Further, they call into question the accuracy and validity of the findings of a recent Journal article and accompanying editorial, which concluded that vigorous forms of exercise that entail breaking into a sweat actually increase the risk for future knee replacement ${ }^{13,14}$.

As an alternative - or at least complementary - perspective, consider the findings of Wang, et al ${ }^{13}$. Twenty-five years ago, a pair of influential articles published in the Journal of the American Medical Association examined the association of running with $\mathrm{OA}^{15,16}$. Running, in vogue at the time, had generated tremendous lay interest. Concomitantly, there was concern that running might hasten, rather than delay, the development of OA in weight-bearing joints. The first study compared clinical and radiographic evidence of $\mathrm{OA}$ at the knee joint among 41 long-distance runners in relation to 41 age, sex, education, and occupation-matched community controls ${ }^{15}$. The runners, members of the 50-Plus Runners Association, were 50 to 72 years of age at entry. They exercised an average of $286 \mathrm{~min}$ per week (the equivalent of $\sim 40 \mathrm{~min}$ daily) compared to $71 \mathrm{~min}$ per week in the comparison group. Notably, whereas the knee radiographs of the female runners demonstrated more radiographic evidence of spur formation and sclerosis than those of the non-runners $(\mathrm{p}<0.001)$, there was no difference in joint space width between the 2 groups, among the men or the women.

The second study focused on men alone, and compared 17 runners with 19 non-runners ${ }^{16}$. All participants were at least 50 years of age. The runners uniformly ran a minimum of $32 \mathrm{~km}$ ( $\sim 20$ miles) each week, during each of the preceding 5 years. Among the runners, $53 \%$ were marathoners. The non-runners, in marked contrast, were for the most part entirely sedentary. Notably, there were no statistically significant differences between the 2 groups in terms of osteophyte formation or cartilage thickness, or in overall radiographic grade of OA. In concert, these initial reports diminished concern that running had a deleterious effect on the structural integrity of the knee joint.

However, these studies had limitations, particularly the relatively small number of participants, limiting statistical power to detect small differences between the groups. In addition, in both studies the runners were 50 years of age or older at initial assessment. Their demographic profile begs the question as to whether these longterm long-distance runners were representative of the running population as a whole. Were they a select group with the anatomically healthiest knees, a group who had not previously sustained a structurally compromising injury during the extended

$$
\text { See OA, exercise, and knee replacement, page } 669
$$


course of running in their earlier adult years $(20 \mathrm{~s}, 30 \mathrm{~s}$, and 40 s) that might have prematurely ended their running activity? Were these runners too select a group from which to infer that running is safe, vis-à-vis risk of incident OA, in the general population?

Therefore, to examine the relationship of exercise to incident OA with large numbers of participants, both in the denominator (the referent population being studied) and in the numerator (the subset who develop the outcome of interest), a population-based community study offers substantial methodologic strength. In this manner, 18 years ago, a report from the Framingham Study examining habitual physical activity and its relation to knee OA was published in The Journal $^{17}$. From among the original cohort, first assembled in 1948-1951, a total of 1415 residents from Framingham, MA, USA, underwent a weight-bearing knee radiograph at the 18th biennial examination (1983-1985). The exposure of interest, physical activity, was ascertained at biennial examinations 4 (1954-1957) and 12 (1971-1973). Each participant was queried regarding the number of hours spent on a typical day according to level of activity: "heavy" [heavy household work or intensive exercise (e.g., jogging)], "moderate" (housework, yard chores, climbing stairs, bowling), "slight" (standing or walking), and "sedentary" (time spent sitting). The 24-h sum of these weighted variables was averaged over the 2 periods of ascertainment, and then analyzed according to quartiles of the measure's distribution. Among the men in the study, $16 \%$ later developed knee OA compared to $18 \%$ of the Framingham women. Importantly, in sex-specific analyses, the higher quartiles of physical activity did not confer a statistically significant increase in risk for future knee OA compared to the lowest, most sedentary level. Yet, interestingly, men at the highest quartile had a 2 -fold increase in risk of osteophyte formation at the knee joint.

Thereafter, as the Framingham participants further aged, the association of physical activity with incident knee OA was revisited after an additional set of knee radiographs was obtained at the 22nd biennial examination $(1992-1993)^{18}$. This time, the approximate 8 -year interval between the 18 th and 22nd examinations constituted the time interval of study. In addition, information about physical activity status, both vocational and leisure-time activity, was re-assessed at the 20th biennial examination (1988-1989). In the same report, the cohort members with the highest daily levels of heavy physical activity experienced a remarkably elevated rate of incident knee OA (adjusted OR: 7 and 9 for the men and women, respectively).

Then, in February 2011, The Journal published an informative report from the Melbourne Collaborative Cohort Study (MCCS), which examined the relationship of leisure time physical activity to incident primary knee replacement surgery ${ }^{13}$. At baseline, the MCCS participants were queried regarding their level of physical activity over the preceding 6-month period. Physical activity was categorized as "vigorous" (e.g., swimming, tennis, netball, athletics, and running, forms of exercise "making you sweat or feel out of breath"); "less vigorous" (e.g., exercise for recreation, sport, or health and fitness, not resulting in sweating or feeling out of breath); the frequency of walking was also recorded. Subsequently, beginning in 2001 and concluding in 2005, each MCCS participant was linked to a national knee (and hip) replacement surgery database. Notably, the MCCS participants who engaged in vigorous activity were at $40 \%$ greater risk to subsequently undergo primary knee replacement surgery.

A design benefit of the Melbourne cohort is its rooting in the general population. As with the Framingham cohort, these are rigorous population-based studies that examined the association of exercise to subsequent knee replacement surgery or radiographic OA. These reports indicate that the association of exercise with incident $\mathrm{OA}$ is not an all-or-nothing proposition, neither uniformly beneficial nor uniformly harmful. A subset of the general population, in studies from both the United States and Australia, experience a higher rate of incident OA than their less-active counterparts.

Importantly, why some members of the population who engage in exercise may increase their risk of future OA is not certain. One possible explanation may be an exercise-related risk of incurring an injury to a meniscus, ligament, tendon and/or muscle. A joint injury is an accepted known risk factor for $\mathrm{OA}^{19,20}$. Such an injury, when severe, is overt and prompts immediate medical attention. But less overt, subclinical, or occult injuries to joint structure may enhance the risk of future OA at the knee. Conceivably, the deleterious effect after an occult injury may be further aggravated by continued engagement in high levels of vigorous exercise. There are potential hazards from exercise to musculoskeletal well-being. When advocating to an otherwise healthy young adult that regular, vigorous exercise throughout adulthood (notwithstanding its many touted benefits) is an absolute, unequivocal win-win proposition, a rheumatologist might well consider including a modest cautionary note.

\author{
ALLAN C. GELBER, MD, MPH, PhD, \\ Associate Professor of Medicine, \\ Deputy Director for Education, \\ Division of Rheumatology, \\ Johns Hopkins University School of Medicine, \\ 5200 Eastern Avenue, Mason F. Lord Bldg., \\ Center Tower, Suite 4100, \\ Baltimore, MD 21224, USA.
}

Address correspondence to Dr. Gelber; E-mail: agelber@jhmi.edu

\section{REFERENCES}

1. Keenan NL, Shaw KM. Coronary heart disease and stroke deaths United States, 2006. MMWR Surveill Summ 2011;60 Suppl:62-6. 
2. Stewart SL, King JB, Thompson TD, Friedman C, Wingo PA. Cancer mortality surveillance--United States, 1990-2000. MMWR Surveill Summ 2004;53:1-108.

3. Frieden TR, Berwick DM. The "Million Hearts" initiative--preventing heart attacks and strokes. N Engl J Med 2011;365:e27.

4. Ezzati M, Lopez AD. Estimates of global mortality attributable to smoking in 2000. Lancet 2003;362:847-52.

5. Gu D, Kelly TN, Wu X, Chen J, Samet JM, Huang JF, et al. Mortality attributable to smoking in China. N Engl J Med 2009;360:150-9.

6. Thun MJ, Peto R, Lopez AD, Monaco JH, Henley SJ, Heath CW Jr, et al. Alcohol consumption and mortality among middle-aged and elderly U.S. adults. N Engl J Med 1997;337:1705-14.

7. Paffenbarger RS Jr, Hyde RT, Wing AL, Hsieh CC. Physical activity, all-cause mortality, and longevity of college alumni. N Engl J Med 1986;314:605-13.

8. Blair SN, Kohl HW, III, Paffenbarger RS Jr, Clark DG, Cooper KH, Gibbons LW. Physical fitness and all-cause mortality. A prospective study of healthy men and women. JAMA 1989;262:2395-401.

9. Paffenbarger RS Jr, Hyde RT, Wing AL, Lee IM, Jung DL, Kampert JB. The association of changes in physical-activity level and other lifestyle characteristics with mortality among men. N Engl J Med 1993;328:538-45

10. Sandvik L, Erikssen J, Thaulow E, Erikssen G, Mundal R, Rodahl K. Physical fitness as a predictor of mortality among healthy, middle-aged Norwegian men. N Engl J Med 1993;328:533-7.

11. Manson JE, Greenland P, LaCroix AZ, Stefanick ML, Mouton CP, Oberman A, et al. Walking compared with vigorous exercise for the prevention of cardiovascular events in women. N Engl J Med 2002;347:716-25.
12. Fries JF, Bruce B, Shoor S. Osteoarthritis, exercise, and knee replacement. J Rheumatol 2012;39:669-71.

13. Wang Y, Simpson JA, Wluka AE, Teichtahl AJ, English DR, Giles $\mathrm{GG}$, et al. Is physical activity a risk factor for primary knee or hip replacement due to osteoarthritis? A prospective cohort study. J Rheumatol 2011;38:350-7.

14. Gelber AC. Breaking into a sweat... and risk of osteoarthritis! J Rheumatol 2011;38:188-90.

15. Lane NE, Bloch DA, Jones HH, Marshall WH Jr, Wood PD, Fries JF. Long-distance running, bone density, and osteoarthritis. JAMA 1986;255:1147-51.

16. Panush RS, Schmidt C, Caldwell JR, Edwards NL, Longley S, Yonker R, et al. Is running associated with degenerative joint disease? JAMA 1986;255:1152-4

17. Hannan MT, Felson DT, Anderson JJ, Naimark A. Habitual physical activity is not associated with knee osteoarthritis: the Framingham Study. J Rheumatol 1993;20:704-9.

18. McAlindon TE, Wilson PW, Aliabadi P, Weissman B, Felson DT. Level of physical activity and the risk of radiographic and symptomatic knee osteoarthritis in the elderly: the Framingham study. Am J Med 1999;106:151-7.

19. Davis MA, Ettinger WH, Neuhaus JM, Cho SA, Hauck WW. The association of knee injury and obesity with unilateral and bilateral osteoarthritis of the knee. Am J Epidemiol 1989;130:278-88.

20. Gelber AC, Hochberg MC, Mead LA, Wang NY, Wigley FM, Klag MJ. Joint injury in young adults and risk for subsequent knee and hip osteoarthritis. Ann Intern Med 2000;133:321-8.

J Rheumatol 2012;39:672-4; doi:10.3899/jrheum.111340 